\title{
Electrophysiologic Effects of Intracellular Lysophosphoglycerides and Their Accumulation in Cardiac Lymph with Myocardial Ischemia in Dogs
}

\author{
Hozuka Akita, Michael H. Creer, Kathryn A. Yamada, Burton E. Sobel, and Peter B. Corr \\ Cardiovascular Division, Department of Medicine, and Department of Pharmacology, Washington University School of Medicine, \\ St. Louis, Missouri 63110
}

\begin{abstract}
Lysophosphatidylcholine (LPC) accumulates in ischemic tissue, and exogenous LPC (20-100 $\mu \mathrm{M})$ induces electrophysiologic alterations in vitro. However, to determine whether compartmentalization is critical, intracellular pressure microinjection of LPC was performed with simultaneous recording of the transmembrane action potential. Intracellular LPC in concentrations as high as $500 \mu \mathrm{M}(n=18)$, calculated based on calibration of injectate volume and cellular volume, did not induce electrophysiologic alterations. The concentrations and efflux of phospholipids and lysophospholipids were assessed in lymph obtained from the supracardiac lymph vessel in anesthetized dogs to assess the extent of extracellular accumulation. Prior to ischemia, phosphatidylcholine (PC) was the major phospholipid in lymph (79 $\pm 2 \%)$ with substantial quantities of sphingomyelin $(11 \pm 2 \%)$ and LPC (6 $\pm 1 \%)$. With ischemia, the concentration of LPC increased by $18 \%$, and net efflux of LPC increased by $24 \%$ (P $<0.01$ ) with no net efflux of PC or other assayed phospholipids. The calculated concentration of LPC increased from 84 to 197 $\mu \mathrm{M}$ in lymph within the ischemic region, a concentration sufficient to induce electrophysiologic derangements.
\end{abstract}

\section{Introduction}

Lethal arrhythmias induced by myocardial ischemia account for most deaths attributable to coronary artery disease (1). In experimental animals, such arrhythmias can occur early after the onset of ischemia and well before morphologic alterations appear in tissue. Metabolites accumulating in ischemic myocardium appear to influence membrane integrity and to mediate many of the electrophysiologic derangements characteristically seen with ischemia in vivo $(2,3)$. Lysophosphoglycerides have been found to accumulate in samples of ischemic tissue in vivo, in venular effluents from ischemic regions in vivo, and in effluents from isolated hearts rendered ischemic (4-7). Net changes in the concentration of lysophosphatidylcholine (LPC) ${ }^{1}$ in tissue comparable to those seen in ischemic tissue in vivo induce analogous, reversible electrophysiologic derangements in normoxic

Address reprint requests to Dr. Corr, Washington University School of Medicine, Box 8086, 660 South Euclid Avenue, St. Louis, MO 63110. 1986.

Received for publication 26 August 1985 and in revised form 11 March

1. Abbreviations used in this paper: DMA, dimethylacetal; FAME, fatty acid methyl esters; LAD, left anterior descending (coronary artery); LPC, lysophosphatidylcholine; PC, phosphatidylcholine; TLC, thin-layer chromatography.

J. Clin. Invest.

(C) The American Society for Clinical Investigation, Inc.

0021-9738/86/07/0271/10 \$1.00

Volume 78, July 1986, 271-280 tissue in vitro (7-12). Electron microscopic autoradiography demonstrates that incorporation of $\left[{ }^{14} \mathrm{C}\right]$ LPC comprising $<2 \mathrm{~mol}$ $\%$ of sarcolemmal phospholipid is sufficient to elicit profound electrophysiologic derangements in isolated ventricular muscle $(13,14)$. Because sarcolemmal phospholipid comprises only $4 \%$ of total cellular phospholipid, even very modest increases of total cellular LPC are likely to be arrhythmogenic if lysophosphoglycerides accumulate selectively in the cell membrane, as appears to be the case (15).

Sites of enhanced production or decreased catabolism accounting for accumulation of lysophosphoglycerides with ischemia have not yet been elucidated. Some of the accumulation may be intracellular. Previous studies have characterized the electrophysiologic effects induced by lysophosphoglycerides delivered extracellularly $(7-10,12)$. However, it is not clear whether increased intracellular concentrations of lysophosphoglycerides result in analogous electrophysiologic alterations. Some of the accumulation appears to be extracellular. The concentration of LPC increases within $10 \mathrm{~min}$ after the onset of ischemia in venular effluents from ischemic zones (5). If a proportionality exists between concentrations in plasma and in interstitial fluid, lysophosphoglycerides may be impinging on the external surface of sarcolemma. In ischemic isolated perfused hearts (4), the concentrations of lysophosphoglycerides increase in effluents as well as in tissue, compatible with either release into the interstitial fluid of intracellularly accumulated material or with direct, extracellular accumulation. In addition, early reperfusion rapidly reverses the electrophysiologic derangements induced by ischemia (3). This observation is consistent with the view that at least some of the accumulating lysophosphoglycerides may be extracellular. Although lymph is not identical to tissue fluid, concentrations of specific moieties in lymph often parallel concentrations in compartments with direct access to the sarcolemma and may reflect metabolic activity at the cell surface $(16,17)$.

In view of these considerations, the present study was performed to determine whether augmentation of the intracellular concentration of LPC elicited by pressure microinjection induces electrophysiologic alterations analogous to changes induced by increased concentrations of extracellular lyșophosphoglycerides. It was performed also to determine whether characteristic changes in the concentrations of extracellular lysophosphoglycerides occur with ischemia in vivo judging from assay of lymph draining zones subjected to ischemia.

\section{Methods}

Electrophysiologic procedures. Adult mongrel dogs of either gender were anesthetized with sodium thiopental $(10 \mathrm{mg} / \mathrm{kg})$, and the hearts were rapidly removed and placed in oxygenated Krebs solution. Purkinje fibers were dissected from both the right and left ventricles. For the pressure microinjection studies, it was essential to utilize small, thin Purkinje fibers to minimize changes in the microelectrode tip resistance otherwise encountered when cells were penetrated. The fibers were attached to 
small glass coverslips with a pin, placed in a 5-ml plexiglass chamber located on the stage of a Nikon microscope (Nikon, Inc., Garden City, $\mathrm{NY}$ ) and superfused continuously with modified Krebs solution at $37^{\circ} \mathrm{C}$ containing in (meq/liter): $\mathrm{Na}^{+} 150 ; \mathrm{K}^{+} 4.0 ; \mathrm{Mg}^{2+} 2.0 ; \mathrm{Ca}^{2+} 2.4 ; \mathrm{Cl}^{-} 136$; $\mathrm{H}_{2} \mathrm{PO}_{4}^{-} 0.9 ; \mathrm{HCO}_{3}^{-} 11.0$; and glucose $5.0 \mathrm{mmol} / \mathrm{liter}$. Buffer was oxygenated by continuous gassing with $95 \% \mathrm{O}_{2} / 5 \% \mathrm{CO}_{2}$ and maintained at $37^{\circ} \mathrm{C}$ (pH 7.30-7.35). The buffer was made acidic (pH 6.6) by gassing with $75 \% \mathrm{O}_{2} / 25 \% \mathrm{CO}_{2}$. The glass used for making the microelectrodes for pressure microinjection was washed in boiling ethanol, rinsed several times with distilled water, and dried. Microelectrodes were pulled on a Brown-Flaming electrode puller (Sutter Instrument Co., San Francisco, CA) with a narrow box filament $(1.5 \mathrm{~mm})$ to construct a tapered tip convenient for pressure microinjection. When filled with $1 \mathrm{M} \mathrm{KCl}$, the microelectrodes exhibited resistances ranging from 30 to $60 \mathrm{M} \Omega$. The microelectrodes were beveled with a WPI beveling system (W-P Instruments, Inc., New Haven, CT) to facilitate penetration of the cells and delivery of fluid during pressure application. Beveled and filled microelectrodes exhibited resistances of $<20 \mathrm{M} \Omega$.

Pressure microinjection was performed with a Picospritzer system (General Valve Corp., Fairfield, NJ) that permits rapid and reproducible ejection of picoliter volumes from the microelectrodes while intracellular action potentials are recorded simultaneously. The Picospritzer was connected to a compressed nitrogen tank. Pressure and injection time were regulated under the control of a solenoid-operated three-way valve, which when inactivated connected the microelectrode to atmospheric pressure, and when activated, permitted the application of a positive pressure pulse (up to $100 \mathrm{psi}$ ) to the microelectrode. The microelectrode was held in a WPI micropipette holder that provided a leak-proof seal and was positioned with a Narishige micromanipulator (Narishige Scientific Instrument Laboratory, Tokyo, Japan). Simultaneous intracellular action potential recording and injection were accomplished with the same microelectrode. Microelectrodes were calibrated with a microscopic ocular micrometer yielding measurements of the diameter of droplets released into mineral oil under increasing pressure and pulse duration. The volume delivered by pressure injection was linearly related to pulse duration as shown in Fig. 1. Electrophysiologic data obtained during pressure microinjection were accepted for analysis only when the calibration curves prior to and after the injections were reproducible. Signals were processed sequentially through a high-impedance unity gain electrometer (WPI,

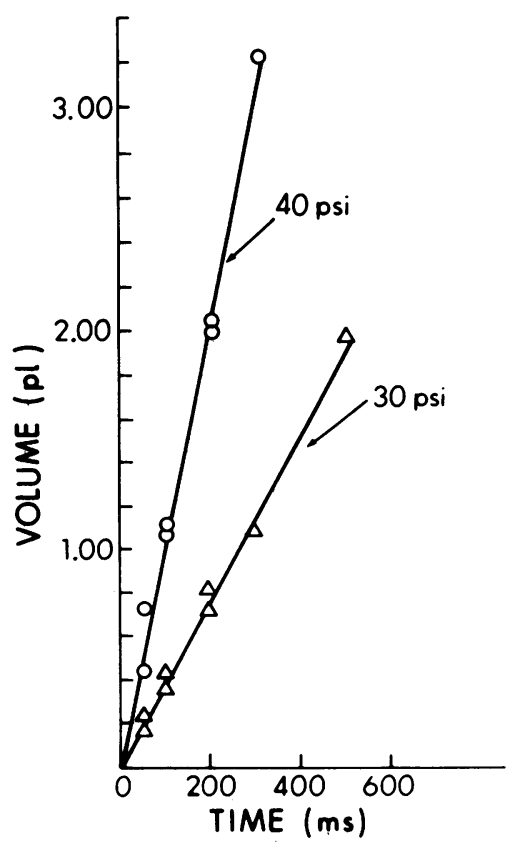

Figure 1. Representative calibration curve for pressure microinjection demonstrating the linearity of release of volume with time at pressures of 30 and 40 psi. model M4A), a constant-gain operational amplifier $(\times 50)$, and a variablegain amplifier before storage on FM analogue tape. Action potential recordings, stored on analogue tape, were analyzed off-line with an automated system (18).

Assuming that the volume injected into the cytosol is similar to that released in mineral oil during calibration and that the LPC diffuses freely throughout the cell as shown previously by autoradiography (13), we estimated the augmentation of the intracellular concentration of LPC achieved. Cell volume was calculated to be $0.1 \mathrm{nl}$ based on a cylindrical cell model with a $20-\mu \mathrm{m}$ radius and $100 \mu \mathrm{m}$ length $\left(1.26 \times 10^{5} \mu \mathrm{m}^{3}\right.$ or $0.1 \mathrm{nl})$. In most experiments intracellular injection was initiated at a low pressure which was gradually increased.

Experiments performed to validate the pressure microinjection system involved intracellular injection of cyclic AMP into canine Purkinje cells. The microelectrode was back-filled with a solution of $\mathrm{KCl}(1 \mathrm{M})$ containing cyclic AMP (1 M), and the microelectrode was calibrated by injection into mineral oil. After continuous acquisition of intracellular recordings had been documented, the cells were depolarized by superfusion with $\mathrm{Krebs}$ buffer containing $10 \mathrm{mM} \mathrm{KCl}$ to inactivate the fast sodium channel. They were then injected with cyclic AMP to activate the slow inward current (Fig. 2). Slow-response action potentials were elicited within $3 \mathrm{~s}$. Within $30 \mathrm{~s}$ after termination of the pressure injection, slow-response action potentials were no longer evident. Superfusion with a phosphodiesterase inhibitor, theophylline $(1 \mathrm{mM})$, prolonged the effects of intracellular injection of cyclic AMP. Injection of vehicle alone $(n=7)$ failed to induce slow-response action potentials in tissue depolarized by elevated $\mathrm{K}^{+}$.

To define the effects of elevation of intracellular concentrations of lysophosphoglycerides induced by injection of LPC, LPC was dissolved at concentrations of 10 or $20 \mathrm{mM}$ in a $1 \mathrm{M} \mathrm{KCl}$ solution, or at concentrations of 30,40 , or $50 \mathrm{mM}$ in an ethanol solution containing choline chloride (1 M). Choline chloride-ethanol was used to enhance the solubility of LPC at higher concentrations and to facilitate ejection of the solution under pressure by reducing viscocity compared with that of an aqueous solution. Thus, lower pressures were required for ejection and delivery of a given amount of LPC in ethanol.

Acquisition of cardiac lymph. Adult mongrel dogs of either sex were anesthetized with sodium pentobarbital $(30 \mathrm{mg} / \mathrm{kg})$ and ventilated with a Harvard respirator to maintain arterial blood gases and $\mathrm{pH}$ within the physiologic range. Additional pentobarbital was administered as needed to maintain a surgical plane of anesthesia. Polyethylene catheters were inserted into the femoral vein and into the femoral artery for recording of the arterial blood pressure with a Statham transducer (Gould Inc., Cleveland, $\mathrm{OH}$ ) connected to a Gould model 260 recorder (Gould, Inc., Recording Systems Div., Cleveland, $\mathrm{OH}$ ). The lead II surface ECG was monitored throughout each experiment.
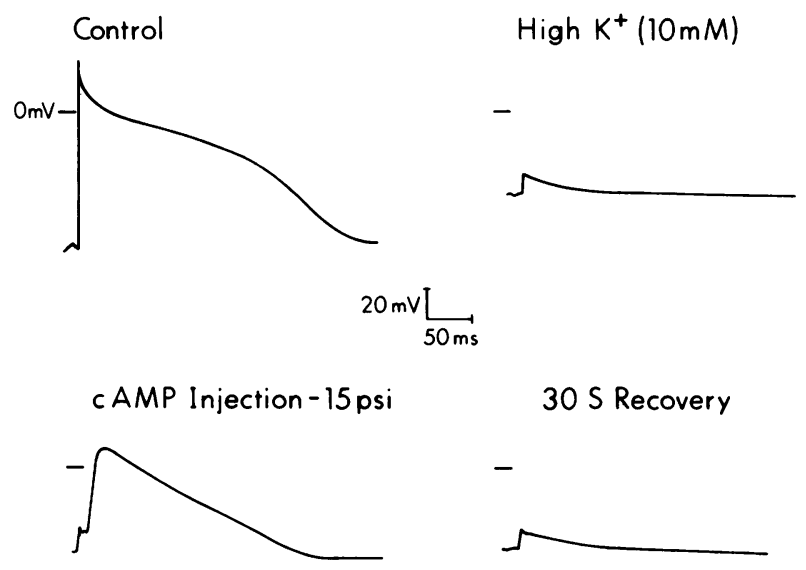

Figure 2. Representative results from an experiment illustrating the effects of intracellular injection of cyclic AMP (cAMP) in the presence of elevated extracellular $\mathrm{K}^{+}$. The calibration bars apply to all four tracings. 
The chest was opened with a median sternotomy, and the pericardium was incised along the anterior interventricular sulcus. Care was taken to prevent contamination of the cardiac lymph with blood by avoiding bleeding from the pericardium. Evan's Blue dye $(0.5 \%, 100 \mu \mathrm{l})$ was injected into the left ventricular subepicardium at the apex to permit visualization of the cardiac lymphatics, usually evident within 5 min after injection of dye. Careful dissection of the cardiac lymph node, situated between the superior caval vein and brachiocephalic artery, exposed the cardiac lymph vessels. All visibly stained vessels were carefully ligated with 5-0 silk. A $22 \mathrm{G}$ intravenous, teflon placement unit (Deseret Medical, Inc., Sandy, UT) was inserted toward the heart into the largest lymphatic vessel caudal to the node. The end of the catheter was cut and connected to polyethylene tubing (PE-60, Clay Adams, Parsippany, NJ) filled with heparin. No heparin was given systemically. A 5-0 silk suture was placed around the catheter to avoid dislodgement while lymph was subsequently collected.

The left anterior descending (LAD) coronary artery was isolated just proximal to the first diagonal branch with care to avoid interference with flow in the lymphatic vessels coursing adjacent to the coronary artery. A 2-0 silk suture was placed loosely around the coronary artery so that it could be occluded by clamping a snare of polyethylene tubing onto the suture.

After the lymph had become transparent as residual dye was cleared, lymph was collected continuously in glass tubes on ice containing $3.8 \%$ sodium citrate as an anticoagulant. Samples were collected every $15 \mathrm{~min}$ and volumes recorded. After a 1-h control period, the LAD coronary artery was ligated for $2 \mathrm{~h}$. Lymph was collected every $15 \mathrm{~min}$ throughout the 2-h interval of ischemia. Lymph samples were frozen rapidly $\left(-70^{\circ} \mathrm{C}\right)$ for subsequent extraction and quantification of phospholipids and protein. At the end of the 2-h interval of ischemia, the tissue was reperfused for 1-h, and Evan's Blue dye was injected again into the left ventricular apex with simultaneous collection of the cardiac lymph until the lymph became dark blue confirming that the collected lymph had originated from the ischemic region.

An additional four dogs served as sham operated controls and were prepared similarly except that the LAD coronary artery was not ligated. Cardiac lymph was collected every $15 \mathrm{~min}$ for $2 \mathrm{~h}$.

Several methodologic problems required evaluation. Supracardiac lymph originates not only from the heart but also from the pericardium, mediastinal tissue, and lung (19). Extracardiac contributions could dilute an increase in lysophosphoglycerides attributable to drainage of an ischemic region of the heart. In addition, influx of fluid into the lymph vessels from the extralymphatic space could occur (16). Furthermore, the composition of cardiac lymph could be altered by passage through the pretracheal lymph node $(20,21)$ which harbors cells, including lymphocytes, known to contain phospholipases (22) and lysolecithin-acyl transferase (23). Previous results from our laboratory obtained with ${ }^{99 m} \mathrm{Tc}$ sulfur colloid injected into selected intramural layers of the heart and serial imaging with a scintillation camera indicate that lymph from anterior regions of the heart, supplied by the LAD coronary artery, drains consistently into the cardiac lymph node (24).

To assess the extent of dilution of cardiac lymph, experiments were performed with simultaneous cannulation of the anterior intraventricular epicardial lymph vessel that receives input from the anterior region of the heart supplied by the LAD coronary artery. Cannulation of the epicardial lymph vessel was performed with a $30 \mathrm{G}$ needle attached to flexible polyethylene tubing (PE10). Because the volume of lymph required for accurate analysis of phospholipid content was far in excess of that obtainable within 10-15 min by cannulation of the epicardial lymph vessel alone, these experiments were performed only to assess the extent of dilution. Evan's Blue dye ( $0.5 \%)$ was infused continuously $(64 \mu \mathrm{l} / \mathrm{min})$ with a Harvard infusion pump (Harvard Apparatus Co., Inc., S. Natick, MA) into the left ventricular apex before insertion of the catheter into the epicardial lymph vessel. Samples from the supracardiac lymph vessel were obtained continuously until the concentration of dye in the lymph determined by spectrophotometric measurements of absorbance at 620 $\mathrm{nm}$ plateaued in at least three sequentially obtained samples. The LAD coronary artery was then ligated, the epicardial vessel was cannulated, and absorbance at $620 \mathrm{~nm}$ in the lymph sample was assessed. The con- centration difference corresponding to absorbance of dye in lymph from the epicardial lymphatic vessel with respect to that from the supracardiac lymphatic vessel was calculated to define the extent of dilution. In six other animals, epicardial lymph samples were collected over a 1-h interval for measurements of phospholipid content under control conditions without ischemia. Because of volume constraints, only one sample could be obtained during each 1 -h interval.

Measurement of phospholipids in cardiac lymph. The extent of possible alterations of the phospholipid content of lymph during the collection interval and storage period prior to analysis was determined. $\left[{ }^{14} \mathrm{C}\right] \mathrm{LPC}\left(1.4 \times 10^{5} \mathrm{dpm}, 1-\left[{ }^{14} \mathrm{C}\right]\right.$ palmitoyl-LPC, New England Nuclear, Boston, MA, specific activity, $55 \mu \mathrm{Ci} / \mu \mathrm{mol}$ ) and $20 \mathrm{nmol}$ soybean LPC (Sigma Chemical Co., St. Louis, MO) were dried under $\mathrm{N}_{2}$ and resuspendéd in either $200 \mu \mathrm{l}$ of Krebs solution or $200 \mu \mathrm{l}$ of freshly collected cardiac lymph to give a final concentration of LPC of $100 \mu \mathrm{M}$. $\left[{ }^{14} \mathrm{C}\right]$ phosphatidylcholine (PC) $\left(5.9 \times 10^{5} \mathrm{dpm} 1,2-\left[{ }^{14} \mathrm{C}\right]\right.$-dioleoyl-PC, New England Nuclear, specific activity, $105 \mu \mathrm{Ci} / \mu \mathrm{mol}$ ) and $20 \mathrm{nmols}$ bovine heart PC were dried under $\mathrm{N}_{2}$ and dissolved in either $200 \mu \mathrm{l}$ of Krebs solution or $200 \mu \mathrm{l}$ of cardiac lymph to give a final concentration of PC of $100 \mu \mathrm{M}$. The $\left[{ }^{14} \mathrm{C}\right] \mathrm{LPC}$ and $\left[{ }^{14} \mathrm{C}\right] \mathrm{PC}$ samples were incubated for 30 min at $0-4^{\circ} \mathrm{C}$ or for $90 \mathrm{~min}$ at $37^{\circ} \mathrm{C}$. After the incubation, phospholipids were extracted according to the method of Bligh and Dyer (25) and separated by thin-layer chromatography (TLC) on Anasil G plates (Analabs, Foxboro Co., New Haven, $\mathrm{CT}$ ) with a solvent system of $\mathrm{CHCl}_{3}$ : methanol:2\% ammonia (65:25:4 vol/vol/vol). The regions of the TLC plate corresponding to the loci of unlabeled standard LPC, PC, and free fatty acid standards were visualized with $\mathrm{I}_{2}$ vapor and the corresponding loci of ${ }^{14} \mathrm{C}$ standards were scraped into individual scintillation vials. $\mathrm{Ra}$ dioactivity was determined by liquid scintillation spectrometry with quench correction after addition of a ${ }^{14} \mathrm{C}$ internal standard of known activity.

Phospholipids in a known volume of lymph obtained under conditions of normal perfusion or ischemia were extracted with chloroformmethanol according to the method of Bligh and Dyer (25), filtered, and separated into classes based on the composition of the polar headgroup with high performance liquid chromatography as previously described $(26,27)$. Fractions corresponding to each phospholipid class were collected and quantified by microphosphate assay after ashing with $10 \% \mathrm{MgNO}_{3}$ in ethanol (27). Total protein content was determined by the dye binding method of Bradford (28). Protein components of lymph were separated by electrophoresis on agarose gel at $\mathrm{pH} 8.6$ and stained with amido black, and individual fractions were quantified by scanning densitometry.

Because choline phospholipids in canine sarcolemma contain $\sim 60 \%$ plasmalogens (29), experiments were performed to determine whether the LPC fraction in lymph contained lysoplasmalogen. The fatty acid composition of choline phospholipids in $0.5-1.0 \mathrm{ml}$ samples of lymph collected during the control period or during the first 45 min following coronary occlusion was assessed after extraction and HPLC separation of the phospholipids into classes based on polar headgroup composition. The PC and LPC fractions were collected and the solvent contents removed by evaporation under a stream of $\mathrm{N}_{2}$ gas. The phospholipid contents were then hydrolyzed in $1 \mathrm{ml} \mathrm{MeOH} / \mathrm{HCl}$ at $90^{\circ} \mathrm{C}$ for $90 \mathrm{~min}$ and neutralized with $\mathrm{Na}_{2} \mathrm{CO}_{3}$ (solid). The fatty acid methyl esters (FAME) and/or dimethylacetal (DMA) products were extracted three times successively with $1 \mathrm{ml}$ of heptane. The heptane layers were combined and then dried over $\mathrm{Mg}_{2} \mathrm{SO}_{4}$, filtered, and injected onto a $30-\mathrm{mm} \times 0.25$ $\mathrm{mm}$ fused silica capillary gas-chromatography column coated with SP2330 with a split ratio of 5-10:1. Sample constituents were eluted isothermally at $190^{\circ} \mathrm{C}$ with a Varian model 3700 chromatography system (Varian Associates, Inc., Palo Alto, CA) with helium as a carrier gas at a flow rate of $2 \mathrm{ml} / \mathrm{min}$. Components eluting from the column were detected and quantified with a flame ionization detector and Varian 4270 integrator. FAME and DMA molecular species in effluents from the column were identified by comparison of the retention time and electron-impact mass spectrum with results obtained following injection of commercially available FAME standards and DMA derivatives prepared from myocardial sarcolemma as described previously (29).

Statistics. Values are reported as means \pm standard error. Significance 
was determined by paired or nonpaired Student's $t$ test as appropriate. $P$ values of $<0.05$ were considered significant.

\section{Results}

Electrophysiologic effects of LPC delivered intracellularly. 40 experiments with reproducible calibration curves before and after intracellular injection were performed with LPC at a concentration within the microelectrode of either 10 or $20 \mathrm{mM}$ in $1 \mathrm{M}$ $\mathrm{KCl}$. Despite the fact that the calculated augmentation of intracellular concentration ranged from 20 to $200 \mu \mathrm{M}$, no alteration in the active membrane properties were seen. Thus, in marked contrast to the electrophysiologic alterations inducible by extracellular LPC, intracellular LPC even at substantially higher concentrations did not induce electrophysiologic effects.

Intracellular proteins may have rapidly bound the injected LPC, thereby preventing its access to the sarcolemma. Accordingly, additional experiments were performed with $1 \mathrm{M}$ choline chloride in ethanol as the solvent. With this solvent, a concentration of LPC of $50 \mathrm{mM}$ in the microelectrode could be attained. In addition, the output rate from the microelectrode at a given pressure was greater than that attainable with the aqueous solution. The use of a lower pressure for a given volume delivery resulted in even more stable recordings of the action potentials during the injection interval.

Previous results from our laboratory have indicated that a reduction of extracellular $\mathrm{pH}$ to 6.7 results in a threefold increase in the sensitivity of Purkinje fibers to the electrophysiologic effects of extracellular $\operatorname{LPC}(5,9)$. Furthermore, it inhibits the activity of lysophospholipase (30), the cytosolic enzyme primarily responsible for metabolism of LPC. Accordingly, as shown in Fig. 3, $50 \mathrm{mM}$ LPC was injected into canine Purkinje cells at $\mathrm{pH}$ 6.6 Reduction of $\mathrm{pH}$ to 6.6 by itself did not induce significant electrophysiologic alterations. In the experiment illustrated, the application of $40 \mathrm{psi}$ pressure for $1 \mathrm{~s}$ was sufficient to eject $1 \mathrm{pl}$ of the $50 \mathrm{mM}$ LPC microelectrode solution. Because the volume of a canine Purkinje cell is $\sim 100 \mathrm{pl}$, the estimated augmentation of the intracellular concentration of LPC was $500 \mu \mathrm{M}$. Nevertheless, no significant electrophysiologic changes were seen (Fig. 3). The data from 18 experiments are shown in Table I. No significant electrophysiologic effects of $500 \mu \mathrm{M}$ intracellular LPC
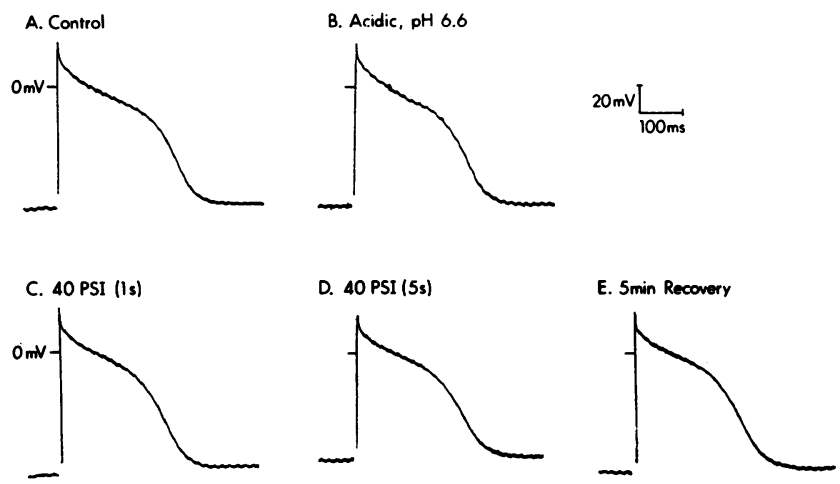

Figure 3. Effect of intracellular injection of $L P C$ at 40 pounds per square inch (PSI) after superfusion of a canine Purkinje fiber with Krebs buffer at pH $6.6(B, C$, and $D)$. Panel $E$ was taken 5 min after pressure microinjection. All tracings were obtained from a single maintained impalement.
Table I. Lack of Effect of Intracellular Injection of LPC on the Transmembrane Action Potential of Purkinje Cells

\begin{tabular}{llllll}
\hline & MDP & AMP & ADP $_{50}$ & ADP $_{70}$ & ADP $_{95}$ \\
\hline & $m V$ & $m V$ & $m s$ & $m s$ & $m s$ \\
$\begin{array}{c}\text { Control } \\
(\mathrm{pH} 6.6)\end{array}$ & $-81 \pm 1$ & $122 \pm 2$ & $172 \pm 7$ & $217 \pm 8$ & $285 \pm 10$ \\
$\begin{array}{c}\text { LPC injection } \\
(500 \mu \mathrm{M})\end{array}$ & $-80 \pm 1$ & $118 \pm 3$ & $177 \pm 7$ & $222 \pm 8$ & $293 \pm 11$ \\
$\begin{array}{c}\text { Recovery } \\
(5 \text { min })\end{array}$ & $-78 \pm 3$ & $115 \pm 5$ & $172 \pm 9$ & $219 \pm 8$ & $288 \pm 13$ \\
\hline
\end{tabular}

Values are means $\pm \operatorname{SEM}(n=18)$. MDP, maximum diastolic potential; $\mathrm{AMP}$, total amplitude; $\mathrm{ADP}_{50}, \mathrm{ADP}_{70}, \mathrm{ADP}_{95}$, action potential duration at $50 \%, 70 \%$, and $95 \%$ of full repolarization, respectively.

were seen. Likewise, injection of a similar volume of the vehicle alone failed to induce electrophysiologic effects.

Phospholipids in cardiac lymph. The flow rate of cardiac lymph from the supracardiac vessel was variable, ranging from 0.6 to $8.7 \mathrm{ml} / \mathrm{h}$ with a mean of $2.3 \pm 0.4 \mathrm{ml} / \mathrm{h}(n=23)$. Lymph flow from the supracardiac lymph vessel during the 1-h control period and $2 \mathrm{~h}$ of ischemia is shown in Fig. 4. Because of the variability of lymph flow from animal to animal, the results were normalized with respect to control flow calculated as the mean flow of the first four 15-min samples. In four sham-operated dogs, lymph flow rate did not change significantly throughout a 2-h collection interval (Fig. 4). In animals with ischemia, cardiac lymph flow gradually decreased by $21 \pm 8 \%$. The decrease of lymph flow with ischemia became significant $(P<0.01) 1 \mathrm{~h}$ after its onset (Fig. 4).

Recovery of phospholipids from cardiac lymph was assessed by adding LPC and PC standards to samples prior to extraction. Recovery was $97-99 \%$ for both phospholipids $(n=5)$. To detect
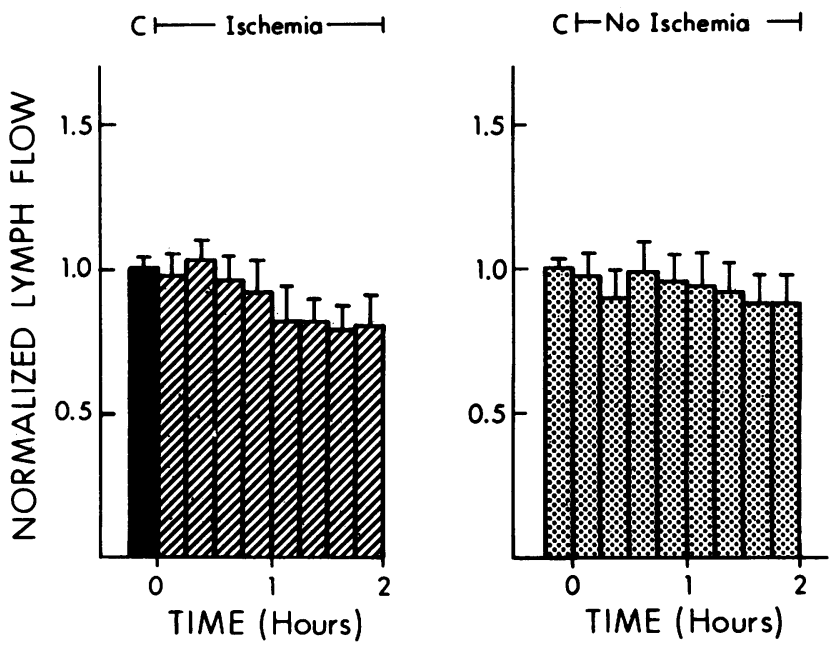

Figure 4. Effect of ischemia on lymph flow from the supracardiac lymph vessel $(l e f t)$. Flow was normalized to the control flow in each animal $(C)$ representing the mean of four 15 -min flow determinations for $1 \mathrm{~h}$ prior to ischemia. Each bar during the 2-h ischemic interval represents flow during a 15 -min interval. On the right are normalized lymph flow values from four sham-operated animals in samples obtained over 2 -h without ischemia. Values are means \pm SEM. 
any conversion of one phospholipid class to another during the sampling and storage procedures, $\left[{ }^{14} \mathrm{C}\right] \mathrm{PC}$ and $\left[{ }^{14} \mathrm{C}\right] \mathrm{LPC}$ were incubated in the presence of cardiac lymph or Krebs buffer for $30 \mathrm{~min}$ at $4^{\circ} \mathrm{C}$. As shown in Table II, virtually no detectable hydrolysis of LPC or PC occurred in lymph. With $\left[{ }^{14} \mathrm{C}\right] \mathrm{LPC}$ incubated in cardiac lymph or Krebs solution at $4^{\circ} \mathrm{C}$ for $30 \mathrm{~min}$, 99\% of the applied material was recovered as intact LPC and $<1 \%$ as PC or free fatty acid. With incubation of $\left[{ }^{14} \mathrm{C}\right] \mathrm{PC}$ in cardiac lymph under the same conditions, $97 \%$ was recovered in the PC fraction and $1 \%$ in the LPC and free fatty acid fractions. With incubation of $\left[{ }^{14} \mathrm{C}\right] \mathrm{PC}$ in Krebs solution under the same conditions, $98 \%$ was recovered in the PC fraction and $1 \%$ in the LPC and free fatty acid fractions.

Additional experiments examined the potential alterations of phospholipid composition in lymph at $37^{\circ} \mathrm{C}$ for $90 \mathrm{~min}$. As shown in Table II, incubation of cardiac lymph at $37^{\circ} \mathrm{C}$ for 90 min resulted in very modest hydrolysis of added LPC. Recovery of label in intact LPC was $96 \%$. It was $1 \%$ and $2 \%$ of the total disintegrations per minute in the PC and free fatty acid fractions, respectively. With incubation of $\left[{ }^{14} \mathrm{C}\right] \mathrm{PC}$ in cardiac lymph under the same conditions, $94 \%, 2 \%$, and $2 \%$ of added disintegrations per minute were recovered in the PC, LPC, and free fatty acid fractions, respectively. Thus, these results confirm the absence of appreciable sampling, intrapreparative, or storage artifact attributable to hydrolysis or interconversion under the sampling and storage conditions used.

The phospholipid composition of 24 samples of normal canine cardiac lymph collected from the supracardiac lymph vessel of nine different animals is shown in Table III. PC comprised $79 \%$ of total phospholipid with a bulk concentration of $1,150 \pm 53$ $\mu \mathrm{M}$. Sphingomyelin comprised $11 \%$ of total phospholipid at a concentration of $153 \pm 6 \mu \mathrm{M}$. LPC comprised $6 \%$ at a concentration of $93 \pm 3 \mu \mathrm{M}$. Phosphatidylinositol (PI), phosphatidylserine (PS), phosphatidylethanolamine (PE), and lysophosphatidylethanolamine (LPE) comprised $\sim 5 \%$ of total phospholipid in aggregate. Lymph obtained from the supracardiac lymph ves-

Table II. Recovery of $\left[{ }^{14} \mathrm{C}\right] L P C$ and $\left[{ }^{14} \mathrm{C}\right] P C$ Standards Added to Canine Cardiac Lymph

\begin{tabular}{lllll}
\hline & & \multicolumn{2}{c}{$\begin{array}{l}\% \text { of total applied dpm } \\
\text { recovered from TLC plate }\end{array}$} \\
\cline { 3 - 5 } Incubation conditions & Sample & $\begin{array}{l}\text { LPC } \\
\text { region }\end{array}$ & $\begin{array}{l}\text { PC } \\
\text { region }\end{array}$ & $\begin{array}{c}\text { FA } \\
\text { region }\end{array}$ \\
\hline & & $\%$ & $\%$ & $\%$ \\
$44^{\circ} \mathrm{C}$ for $30 \mathrm{~min}(n=2)$ & {$\left[{ }^{14} \mathrm{C}\right] \mathrm{PC}+$ buffer } & 1 & 98 & 1 \\
& {$\left[{ }^{14} \mathrm{C}\right] \mathrm{PC}+$ lymph } & 1 & 97 & 1 \\
& {$\left[{ }^{14} \mathrm{C}\right] \mathrm{LPC}+$ buffer } & 99 & $\mathrm{ND}$ & $\mathrm{ND}$ \\
$37^{\circ} \mathrm{C}$ for $90 \mathrm{~min}(n=3)$ & {$\left[{ }^{14} \mathrm{C}\right] \mathrm{LPC}+$ lymph } & 99 & $\mathrm{ND}$ & $\mathrm{ND}$ \\
& {$\left[{ }^{14} \mathrm{C}\right] \mathrm{PC}+$ buffer } & 1 & 97 & 1 \\
& {$\left[{ }^{14} \mathrm{C}\right] \mathrm{PC}+$ lymph } & 2 & 94 & 2 \\
& {$\left[{ }^{14} \mathrm{C}\right] \mathrm{LPC}+$ buffer } & 80 & 1 & 19 \\
& {$\left[{ }^{14} \mathrm{C}\right] \mathrm{LPC}+$ lymph } & 96 & 1 & 2
\end{tabular}

TLC separation was performed as described in Methods. Disintegrations per minute (dpm) were obtained from measured counts per minute (cpm) after correction for quenching with a ${ }^{14} \mathrm{C}$ label used as an internal standard. Values are means of three experiments. FA, fatty acid; ND, not detectable.
Table III. Phospholipid Composition

of Normal Canine Cardiac Lymph

\begin{tabular}{|c|c|c|c|c|}
\hline \multirow[b]{2}{*}{$\begin{array}{l}\text { Phospholipid } \\
\text { class }\end{array}$} & \multicolumn{2}{|c|}{ Supracardiac lymph* } & \multicolumn{2}{|c|}{ Epicardial lymph $\ddagger$} \\
\hline & Concentration & $\begin{array}{l}\text { \% of total } \\
\text { phospholipid }\end{array}$ & Concentration & $\begin{array}{l}\text { \% of total } \\
\text { phospholipid }\end{array}$ \\
\hline & $\mu M$ & $\%$ & $\mu M$ & $\%$ \\
\hline $\mathrm{PI}+\mathrm{PS}$ & $34 \pm 2$ & $2 \pm 0.1$ & $34 \pm 3$ & $2 \pm 0.1$ \\
\hline PE & $22 \pm 2$ & $2 \pm 0.2$ & $32 \pm 5$ & $3 \pm 0.6$ \\
\hline LPE & $12 \pm 2$ & $1 \pm 0.1$ & $16 \pm 7$ & $1 \pm 0.4$ \\
\hline PC & $1,150 \pm 53$ & $79 \pm 0.4$ & $1,283 \pm 142$ & $80 \pm 1.3$ \\
\hline Sphing & $153 \pm 6$ & $11 \pm 0.3$ & $147 \pm 12$ & $9 \pm 0.4$ \\
\hline LPC & $93 \pm 3$ & $6 \pm 0.2$ & $84 \pm 5$ & $6 \pm 0.7$ \\
\hline $\begin{array}{c}\text { Total phos- } \\
\text { pholipid }\end{array}$ & $1,470 \pm 51$ & - & $1,662 \pm 193$ & - \\
\hline
\end{tabular}

Values are means \pm SEM. PI, phosphatidyl inositol; PS, phosphatidyl serine; PE, phosphatidyl ethanolamine; LPE, lysophosphatidyl ethanolamine; PC, phosphatidyl choline; Sphing, sphingomyelin; LPC, lysophosphatidyl choline.

* 24 sample measurements from nine animals.

$\ddagger$ Nine sample measurements from six animals.

sel reflects constituents not only from the heart but also from lung, pericardium, and mediastinum. Its composition may change as it passes through the pretracheal lymph node. However, the phospholipid composition of samples of lymph from the epicardial lymph vessel on the anterior portion of the heart in six control dogs was virtually indistinguishable from that of lymph from the supracardiac lymph vessel (Table III).

Alterations of the composition of phospholipids in cardiac lymph associated with ischemia and reperfusion. Changes in the concentrations of LPC and PC in supracardiac lymph with $2 \mathrm{~h}$ of ischemia are shown in Fig. 5. LPC increased by $13 \%$ within $15 \mathrm{~min}$ of the onset of ischemia. The increase may have occurred even earlier, but the small volume of lymph available protracted the initial sampling interval required to $15 \mathrm{~min}$. A peak increase of concentration of LPC appeared consistently within $30 \mathrm{~min}$ and averaged $118 \%$ of control values (Fig. 5). This peak contrasted with a decrease of the concentration of LPC seen in corresponding intervals in sham-operated controls (Fig. 5). The initial increase was followed by a decline through the first hour of ischemia and by no change during the second hour.

In contrast to the significant increase in the concentration of LPC in cardiac lymph, there were no significant changes in the concentrations in cardiac lymph of the other phospholipids assayed during the time course of ischemia (Fig. 5).

To evaluate the amount of LPC released into or accumulating in lymph, a normalized net efflux of LPC and PC was calculated for each interval as follows: ([LPC] $\times \dot{V}_{L}$ ) ischemic sample/ $\left([\mathrm{LPC}] \times \dot{V}_{\mathrm{L}}\right)$ mean of three control values, where [LPC] is the concentration $(\mu \mathrm{M})$ of $\mathrm{LPC}, \dot{V}_{\mathrm{L}}$ is the lymph flow rate $(\mathrm{ml} / \mathrm{min})$ with efflux expressed with respect to the normalized control value (1.0).

After $15 \mathrm{~min}$ of ischemia, a $14 \%$ increase in the net efflux of LPC was seen. Efflux returned to control within $45 \mathrm{~min}$ after the onset of ischemia. The peak increase of LPC efflux occurred within $30 \mathrm{~min}$ of ischemia and averaged $24 \%(P<0.01$, Fig. 6$)$. In contrast, there was no significant increase in the net efflux of PC or any of the other phospholipids assayed. The increase of 
C $\longmapsto$ Ischemia $\longrightarrow$

A. LPC Concentration

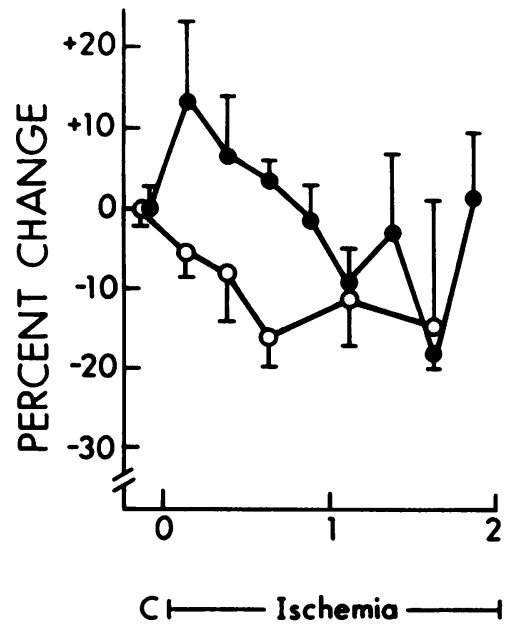

B. PC Concentration

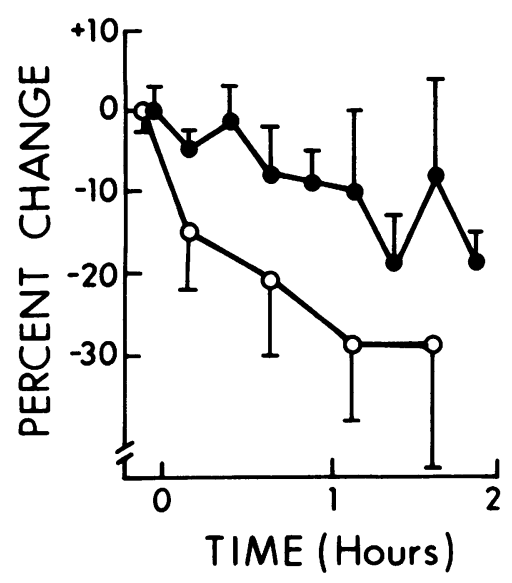

Figure 5. Percent change of the concentration of LPC (top) and PC (bottom) during 2-h intervals of ischemia $(\bullet, n=7)$. Values from sham-operated, nonischemic control animals are shown for each phospholipid (o, $n=4)$. Peak values of LPC (top) and PC (bottom) are shown on the right.

efflux of LPC contrasted to a net decrease of efflux of LPC in sham operated controls (Fig. 6).

Thus, despite the potential dilutional effects of lymph flow from nonischemic regions and extramyocardial sources that could mask changes in concentration and efflux of LPC, significant increases in the concentration and efflux of LPC were seen early after the onset of ischemia. To assess the extent of dilution, Evan's Blue dye was infused continuously into the ventricular tissue at the apex in a region to be rendered ischemic later (see Methods). The concentration of dye was 7.5-fold higher in the epicardial lymph sample compared to that measured in supracardiac lymph. In another similar experiment the calculated dilution factor was 8.8. Assuming that the increase of concentration of LPC with ischemia is attributable exclusively to changes in the ischemic region, the observed $18 \%$ increase of LPC in supracardiac lymph would reflect an actual increase of 7.5 times this value or a net $135 \%$ increase of the concentration of LPC in the epicardial lymph. The concentration of LPC in epicardial
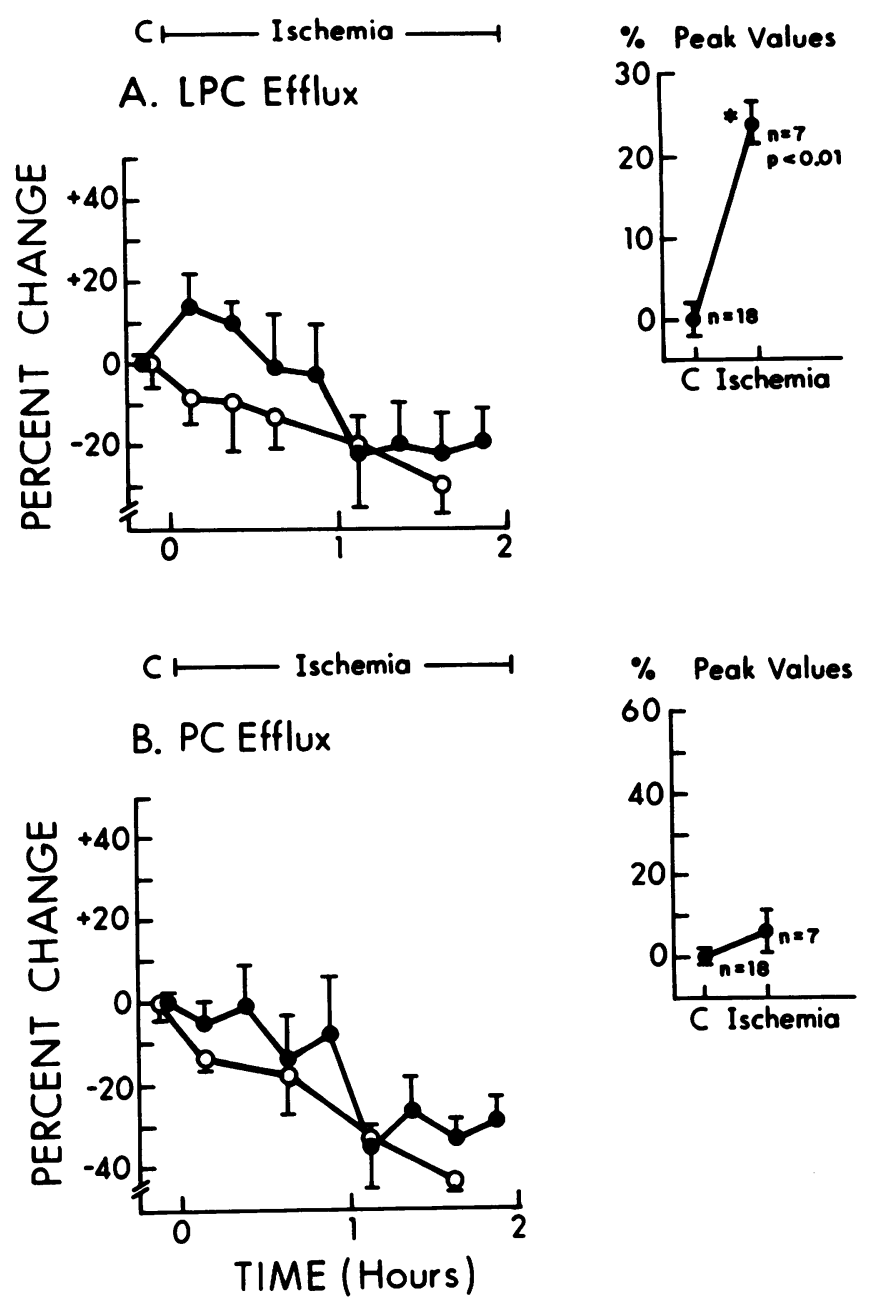

Figure 6. Percent change of the efflux of LPC (top) and PC (bottom) during 2-h intervals of ischemia $(\bullet, n=7)$. Values from sham-operated, nonischemic control animals are shown for each phospholipid $(\mathrm{O}, n=4)$. Peak values of LPC (top) and PC (bottom) are shown on the right.

lymph from normal animals was $84 \pm 5 \mu \mathrm{M}$ (Table III), comparable to that in control, supracardiac lymph prior to coronary occlusion $(79 \pm 0.4 \mu \mathrm{M})$ (Table III). Based on a dilutional factor of 7.5 and a net observed $18 \%$ increase in the concentration of LPC, the actual concentration of LPC in interstitial fluid of the ischemic zone was calculated to be $197 \mu \mathrm{M}$.

The concentration of LPC required to induce electrophysiologic effects is dependent in part on the concentration of protein in the medium (9). Protein composition of serum and cardiac lymph in control conditions and with ischemia is shown in Table IV. The concentration of total protein in control, nonischemic lymph was $20 \%$ lower than that in normal serum. Albumin content of normal cardiac lymph was $1.58 \mathrm{~g} / 100 \mathrm{ml}$ in contrast to $1.44 \mathrm{~g} / 100 \mathrm{ml}$ with ischemia. Although total protein decreases slightly (i.e., by $10 \%$ ) during ischemia, the fractional contribution of albumin does not change. Thus, although the concentration of LPC increases in lymph from ischemic regions, the concentrations of protein and of albumin do not and, in fact, may decline.

In an effort to identify the subcellular locus or loci for the 
Table IV. Comparison of the Protein Composition of Cardiac Lymph with That of Serum

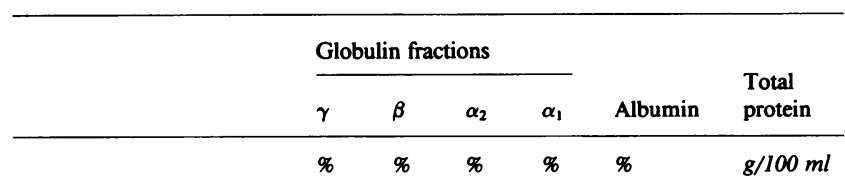

Normal serum

$$
(n=2)
$$$$
13
$$

325

8

10

Lymph from normal

$$
\text { zones }(n=3)
$$

Lymph from ischemic zones $(n=3)$

$\begin{array}{lllll}7 & 32 & 13 & 11 & 36 \\ 7 & 31 & 15 & 11 & 36\end{array}$

5.5
4.4

generation of lysophospholipids in canine cardiac lymph during ischemia, we compared the distribution of molecular species of PC and LPC present in lymph collected during the control and ischemic conditions from the same animal. The characteristic distribution of PC molecular species in myocardial sarcolemma may differ substantially from that of $\mathrm{PC}$ in lymph. If this were the case, the measurement of the distribution of the LPC molecular species in lymph during both the control and ischemic intervals should provide indirect criteria relevant to the question of whether the increase in LPC during ischemia represents LPC generated in situ from sarcolemma or LPC arising from extramyocytic sources. In order to collect sufficient LPC for duplicate analysis of lymph from ischemic zones, it was necessary to combine all samples collected from a given animal during the first 45-min interval after coronary occlusion. The results demonstrate that choline phospholipids in cardiac lymph consist exclusively of O-acyl ester species with no vinyl-ethers (Table V). The presence of substantial $(>10 \%)$ amounts of phospholipid species which contain alkyl-ether groups that are not hydrolyzed by conventional methods employing $\mathrm{HCl} / \mathrm{MeOH}$ (31) was excluded by the lack of demonstrable amounts of LPC remaining after hydrolysis of PC or LPC with $\mathrm{MeOH} / \mathrm{HCl}$ after TLC separation and $\mathrm{I}_{2}$ staining of extracts of the reaction mixtures. Be-

Table V. Fatty Acid Profiles of Choline Phosphoglycerides

\begin{tabular}{|c|c|c|c|c|}
\hline \multirow[b]{3}{*}{ FAME species } & \multicolumn{4}{|c|}{ Relative \% } \\
\hline & \multicolumn{2}{|l|}{ LPC } & \multicolumn{2}{|l|}{ PC } \\
\hline & $\begin{array}{l}\text { Control } \\
\text { zones }\end{array}$ & $\begin{array}{l}\text { Ischemic } \\
\text { zones }\end{array}$ & $\begin{array}{l}\text { Control } \\
\text { zones }\end{array}$ & $\begin{array}{l}\text { Ischemic } \\
\text { zones }\end{array}$ \\
\hline & $\%$ & $\%$ & $\%$ & $\%$ \\
\hline 16:0 & $39 \pm 3$ & $39 \pm 4$ & $16 \pm 2$ & $20 \pm 4$ \\
\hline 18:0 & $36 \pm 2$ & $35 \pm 3$ & $33 \pm 4$ & $25 \pm 3$ \\
\hline $18: 1$ & $12 \pm 2$ & $14 \pm 4$ & $5 \pm 2$ & $9 \pm 3$ \\
\hline 18:2 & $13 \pm 2$ & $12 \pm 3$ & $14 \pm 5$ & $22 \pm 5$ \\
\hline $20: 4$ & $<3$ & $<3$ & $32 \pm 4$ & $24 \pm 5$ \\
\hline
\end{tabular}
in Canine Cardiac Lymph from Control and Ischemic Zones

FAME species are identified by the convention " $a: b$," where $a=$ aliphatic chain length and $b=$ number of double bonds. Values represent the mean $\pm S D$ of two to three measurements. There were no detectable amounts of DMA in either the LPC or PC fractions. cause choline phospholipids present in canine myocardial sarcolemma have been shown recently to be comprised of nearly $60 \%$ plasmalogen molecular species (29), the absence of lysoplasmalogens in cardiac lymph collected under control conditions or with ischemia suggests that the site of production of LPC appearing in lymph is primarily extramyocytic.

\section{Discussion}

The present results demonstrate that concentrations of LPC increase selectively in cardiac lymph from ischemic regions. The calculated twofold increase in concentration to $197 \mu \mathrm{M}$, potentially impinging on the external surface of the sarcolemma, is sufficient to induce profound electrophysiologic effects, particularly in the presence of a concomitant reduction in the extracellular pH to $6.7(5,9)$. The increase occurred primarily during the first $15 \mathrm{~min}$ of ischemia with a progressive fall to control values within $45 \mathrm{~min}$. Thus, it was confined to the interval early after the onset of ischemia with the subsequent decrease likely reflecting a decrease in production or lack of continued extracellular accumulation because of uptake into myocytes. In sham control animals, both the concentration and efflux of LPC decreased rather than increased indicating that the net overall increase with ischemia was higher than the change measured in ischemic lymph alone.

Assessment of the concentration of LPC within the ischemic zone required the use of dye to determine the extent of dilution of lymph from the ischemic region compared with that from the supracardiac lymph node. Two assumptions were made. First, lymph flow within the ischemic region was assumed not to increase during the time course of ischemia. Based on direct measurements, total lymph flow fell slightly with ischemia though significantly decreasing only after $1 \mathrm{~h}$. In experiments performed to determine directly the concentration of LPC in epicardial lymph, the flow decreased markedly during the 1-h ischemic interval. Thus, during ischemia, epicardial lymph flow decreased rather than increased. The second assumption was that the increase in LPC measured from the supracardiac lymph vessel represented changes dependent exclusively on constituents liberated from the ischemic zone. Previous results from our laboratory indicate that the increase in tissue LPC occurs in ischemic but not normal zones of the same heart (7). Thus, it is unlikely that the increases of concentration and efflux of LPC in the supracardiac lymph vessel early after ischemia were attributable to sites other than the ischemic zone. The observations that lymph flow in the epicardial vessel decreased markedly during the first $\mathbf{3 0}$ min of ischemia without a significant decrease of lymph flow in the supracardiac lymph vessel despite an increase in both the concentration and efflux of LPC in supracardiac lymph indicate that the concentration of LPC in the ischemic zone is likely to be even higher than that calculated.

Although the site of production of lysophospholipids in ischemic tissue has not yet been elucidated, these metabolites appear to accumulate in the extracellular space. LPC increases twofold in venular effluents from ischemic regions within $10 \mathrm{~min}$ (5). The fact that electrophysiologic derangements induced by ischemia are rapidly reversible with reperfusion even in the presence of maintained hypoxia (3) suggests that accumulation of metabolites in the extracellular compartment is a critical determinant of the electrophysiologic alterations seen. The fact that venular blood from ischemic regions induces marked electro- 
physiologic alterations in normoxic tissue in vitro (2) suggests that accumulation is, at least in part, extracellular. The results of the present study add further support to the likelihood of an extracellular site of accumulation. In lymph obtained early after the onset of ischemia, the concentration of LPC is sufficient to induce marked electrophysiologic changes. The fact that the LPC present in lymph during control conditions and with ischemia did not contain choline lysoplasmalogens further supports the conclusion that the lysophospholipids in lymph from ischemic zones are not derived from the sarcolemma. Accordingly, the enhanced production or decreased catabolism of LPC may reflect metabolism in vascular smooth muscle, endothelium or, alternatively, in blood cell elements. However, the identification of a phospholipase $\mathrm{A}_{2}$ specific for plasmalogens in canine myocardium (32) suggests that the absence of lysoplasmalogens with ischemia may reflect an activation of phospholipase $A_{2}$ specific for acyl ester PC as opposed to plasmalogens. Thus, the absence of lysoplasmalogen in lymph does not preclude the possibility that LPC may be derived from a myocytic as opposed to an extramyocytic source.

Because of the slow transit of lymph from the ischemic zone to the supracardiac lymph vessel as well as dilution with fluid from noncardiac sources, it was not possible to directly compare the changes in the concentration of LPC in lymph with the occurrence of arrhythmias. All animals developed arrhythmias within the first $5 \mathrm{~min}$ of ischemia, but the severity of ventricular arrhythmias was unrelated to the magnitude of the increase of LPC. It is likely that the extent of heterogeneity of accumulation in interstitium within the ischemic zone, with resultant heterogeneous electrophysiologic alterations, is a critical factor in arrhythmogenesis.

Several observations suggest that lymphatic drainage removes metabolites that contribute to arrhythmogenesis in ischemic myocardium. For example, Rusznyak and colleagues (33) have reported that obstruction of cardiac lymphatics leads to marked changes in the electrocardiogram analogous to those occurring with ischemia including ST-segment depression or elevation, increase in T-wave amplitude, and deep Q waves. Szlavy and colleagues (34) have reported that injection of cardiac lymph obtained from ischemic but not normal hearts into coronary arteries in dogs results in arrhythmias and alterations in the electrocardiogram analogous to those seen with ischemia in vivo. Thus, ischemia appears to elaborate arrhythmogenic metabolites in cardiac lymph. The results of the present study suggest that one such metabolite is LPC. Based on anatomical studies, Uhley and colleagues (35) have hypothesized that cardiac lymphatics may contribute to the development of pathologic lesions of the conduction system either by direct involvement or indirectly by delivering toxic metabolites from a remote, damaged area to the conduction pathways.

The present results demonstrate also that intracellular accumulation of LPC at relatively high concentrations fails to induce electrophysiologic derangements analogous to those seen with extracellular delivery. Extracellular delivery of concentrations of LPC as low as 20-50 $\mu \mathrm{M}$ induce profound and reversible electrophysiologic effects $(7-10,12)$ associated with incorporation of $<1 \%$ of total sarcolemmal phospholipid based on measurements of radiolabeled LPC and electron microscopic autoradiography $(13,14)$. Despite calculated intracellular concentrations of LPC as high as $500 \mu \mathrm{M}$ after pressure microinjection, no apparent electrophysiologic alterations were induced. Thus, either intracellular binding preventing access of LPC to the sarcolemma, intracellular catabolism preventing marked accumulation, or delivery from the cytosolic rather than extracellular side of the sarcolemma precludes marked electrophysiologic perturbations.

The intracellular binding protein in heart ( $\mathrm{Z}$ protein) can bind both fatty acids and fatty acid esters depending on its molecular state (36). Binding of LPC to this protein is likely, judging from the amphipathic structure of LPC and its avid binding to other proteins, including albumin. Intracellular membranes, excluding sarcolemma, comprise $\sim 95 \%$ of the cellular membrane surfaces. Because LPC is readily incorporated into cell membranes, it is likely that much of the injected LPC is incorporated into other cell membrane systems, including the sarcoplasmic reticulum and mitochondria, thereby reducing availability of free LPC for incorporation into the sarcolemma. However, because of the small volumes of injectate that could be made into a single cell, it was not possible to directly measure the subcellular distribution of injected LPC. Previous findings after extracellular delivery of radiolabeled LPC and subsequent electron microscopic autoradiography indicate that LPC diffuses rapidly throughout the intracellular compartment $(13,14)$. Thus, intracellular injection of LPC would likely result in rapid diffusion throughout the intracellular compartment as well.

Intracellular catabolism of LPC could have occurred and accounted for the lack of a potent electrophysiologic effect. However, the major cytosolic catabolic enzyme in heart, lysophospholipase, is inhibited markedly (i.e., $88 \%$ ) by a reduction in $\mathrm{pH}$ to $6.6(30)$, and all injection experiments were performed at this $\mathrm{pH}$. Thus, it is unlikely that intracellular catabolism completely obviated the high levels of intracellular LPC.

It is unlikely also that delivery from the cytosolic side of the sarcolemma would fail to induce electrophysiologic effects analogous to those induced by delivery from the extracellular space if the extent of sarcolemmal incorporation were similar. This conclusion is supported by the very rapid transsarcolemmal movement of LPC (13). Thus, the predilection of extracellular lysophosphoglycerides to induce potent electrophysiologic effects appears to reflect differential binding of intracellular compared with extracellular lysophosphoglycerides.

Although the specific ionic events responsible for the electrophysiologic effects induced by lysophospholipids are not yet clear, several pertinent observations have been made. The rapid inward current carried by $\mathrm{Na}^{+}$is depressed judging from very rapid reductions in $\dot{V}_{\max }$ associated with a downward and rightward shift of the membrane response curve $(8,10)$. Thus, $g_{\mathrm{Na}^{+}}$ appears to be reduced not only as a result of the associated decrease in resting potential but also directly through the interaction of LPC with the sarcolemma. The decrease of resting membrane potential induced by LPC appears to reflect a reduction in outward $\mathrm{K}^{+}$conductance (12). The slow inward current carried by calcium appears to be reduced in magnitude by LPC (12) although intracellular calcium appears to increase with an associated increase in contractility $(12,37)$. This effect of LPC may be secondary to inhibition of sarcolemmal $\mathrm{Na}^{+}-\mathrm{K}^{+}$ATPase (38, 39) with accumulation of intracellular sodium and enhanced $\mathrm{Na}^{+}-\mathrm{Ca}^{2+}$ exchange. Thus, the electrophysiologic effects of LPC delivered from the extracellular compartment appear to be secondary to a reduction in the membrane conductances to $\mathrm{Na}^{+}$, $\mathrm{K}^{+}$, and $\mathrm{Ca}^{2+}$.

In conclusion, the present findings indicate that extracellular 
LPC is a more direct determinant of electrophysiologic derangements than intracellular LPC. With myocardial ischemia in vivo, significant changes are seen in lymphatic fluid indicative of increased concentrations of LPC impinging on the external surface of sarcolemma. These results suggest that pharmacologic interventions designed to inhibit the accumulation of lysophospholipids are likely to be effective as antiarrhythmic interventions particularly if they act preferentially on the extracellular loci responsible for increased production of LPC. Recent observations from our laboratory indicate that intracellular accumulation of long-chain acyl carnitines contributes to the electrophysiologic effects of hypoxia in cultured myocytes (40). If similar phenomena occur with ischemia in vivo, the effects of intracellular long-chain acyl carnitines and extracellular lysophosphoglycerides may be additive in view of the known additive nature of their electrophysiologic effects in vitro $(9,15)$.

\section{Acknowledgments}

The authors wish to express their appreciation to Mr. Roosevelt Dean and Ms. Christine Pastor for technical assistance and to Ms. Ava Ysaguirre for preparation of the manuscript.

This work was supported in part by grant HL-17646, SCOR in Ischemic Heart Disease, grant HL-28995, and grant RR-00396 from the Division of Research Resources, National Institutes of Health. This research was performed during Dr. Corr's tenure of an Established Investigatorship of the American Heart Association and with funds contributed in part by the Missouri Heart Affiliate. Dr. Yamada is supported by a postdoctoral fellowship from the Missouri Heart Association.

\section{References}

1. Armstrong, A., B. Duncan, M. F. Oliver, D. G. Julian, K. W. Donald, M. Fulton, W. Lutz, and S. L. Morrison. 1972. Natural history of acute coronary heart attacks: a community study. Br. Heart J. 34:6780.

2. Downar, E., M. J. Janse, and D. Durrer. 1977. The effect of "ischemic" blood on transmembrane potentials of normal porcine ventricular myocardium. Circulation. 55:455-462.

3. Downar, E., M. J. Janse, and D. Durrer. 1977. The effect of acute coronary artery occlusion on subepicardial transmembrane action potentials on the intact porcine heart. Circulation. 56:217-224.

4. Sobel, B. E., P. B. Corr, A. K. Robison, R. A. Goldstein, F. X. Witkowski, and M. S. Klein. 1978. Accumulation of lysophosphoglycerides with arrhythmogenic properties in ischemic myocardium. J. Clin. Invest. 62:546-553.

5. Snyder, D. W., W. A. Crafford, Jr., J. L. Glashow, D. Rankin, B. E. Sobel, and P. B. Corr. 1981. Lysophosphoglycerides in ischemic myocardium effluents and potentiation of their arrhythmogenic effects. Am. J. Physiol. 241:H700-H707.

6. Shaikh, N. A., and E. Downar. 1981. Time course of changes in porcine myocardial phospholipid levels during ischemia. Circ. Res. 49: 316-325.

7. Corr, P. B., D. W. Snyder, B. I. Lee, R. W. Gross, C. R. Keim, and B. E. Sobel. 1982. Pathophysiological concentrations of lysophosphatides and the slow response. Am. J. Physiol. 243:H187-H195.

8. Corr, P. B., M. E. Cain, F. X. Witkowski, D. A. Price, and B. E. Sobel. 1979. Potential arrhythmogenic electrophysiological derangements in canine Purkinje fibers induced by lysophosphoglycerides. Circ. Res. 44:822-832.

9. Corr, P. B., D. W. Snyder, M. E. Cain, W. A. Crafford, Jr., R. W. Gross, and B. E. Sobel. 1981. Electrophysiological effects of amphiphile on canine Purkinje fibers: implications for dysrhythmia secondary to ischemia. Circ. Res. 49:354-363.
10. Arnsdorf, M. F., and G. J. Sawicki. 1981. The effects of lysophosphatidylcholine, a toxic metabolite of ischemia, on the components of cardiac excitability in sheep Purkinje fibers. Circ. Res. 49:16-30.

11. Man, R. Y. K., and P. C. Choy. 1982. Lysophosphatidylcholine causes cardiac arrhythmia. J. Mol. Cell. Cardiol. 14:173-175.

12. Clarkson, C. W., and R. E. Ten Eick. 1983. On the mechanism of lysophosphatidylcholine-induced depolarization of cat ventricular myocardium. Circ. Res. 52:543-556.

13. Gross, R. W., P. B. Corr, B. I. Lee, J. E. Saffitz, W. A. Crafford, Jr., and B. E. Sobel. 1982. Incorporation of radiolabeled lysophosphatidyl choline into canine Purkinje fibers and ventricular muscle: electrophysiological, biochemical, and autoradiographic correlations. Circ. Res. 51: 27-36.

14. Saffitz, J. E., P. B. Corr, B. I. Lee, R. W. Gross, E. K. Williamson, and B. E. Sobel. 1984. Pathophysiologic concentrations of lysophosphoglycerides quantified by electron microscopic autoradiography. $L a b$. Invest. 50:278-286.

15. Corr, P. B., R. W. Gross, and B. E. Sobel. 1984. Amphipathic metabolites and membrane dysfunction in ischemic myocardium. Circ. Res. 55:135-154.

16. Michael, L. H. 1981. Cardiac lymph: monitor of myocardial membrane and vascular alterations. Life Sci. 29:1495-1505.

17. Miller, A. J. 1982. The formation and flow of cardiac lymph. In Lymphatics of the Heart. Raven Press, New York. 206-261.

18. Witkowski, F. X., and P. B. Corr. 1978. Automated analysis of cardiac intracellular transmembrane action potentials. Comput. Cardiol. September:315-318.

19. Leeds, S. E., H. N. Uhley, and R. B. Meister. 1979. Application of direct cannulation and injection lymphangiography to the study of canine cardiac and pulmonary efferent mediastinal lymphatics. Invest. Radiol. 14:70-78.

20. Adair, T. H., D. S. Moffatt, A. W. Paulsen, and A. C. Guyton: 1982. Quantitation of changes in lymph protein concentration during lymph node transit. Am. J. Physiol. 243:H351-H359.

21. Knox, P., and J. J. Pflug. 1983. The effect of the canine popliteal node on the composition of lymph. J. Physiol. (Lond.). 345:1-14.

22. Resch, K., E. Ferber, J. Odenthal, and F. Fischer. 1971. Early changes in the phospholipid metabolism of lymphocytes following stimulation with phytohemagglutinin and with lysolecithin. Eur. J. Immunol. $1: 162-165$.

23. Ferber, E., K. Resch, D. F. H. Wallach, and W. Imm. 1971. Isolation and characterization of lymphocyte plasma membranes. Biochim. Biophys. Acta. 266:494-504.

24. Clark, G. L., B. A. Siegel, and B. E. Sobel. 1980. External evaluation of regional cardiac lymph drainage in intact dogs. Invest. Radiol. 15:134-139.

25. Bligh, E. G., and W. J. Dyer. 1959. A rapid method of total lipid extraction and purification. Can. J. Biochem. Physiol. 37:911-917.

26. Gross, R. W., and B. E. Sobel. 1980. Isocratic high performance liquid chromatography separation of phosphoglycerides and lysophosphoglycerides. J. Chromatogr. 197:79-85.

27. Creer, M. H., C. Pastor, P. B. Corr, R. W. Gross, and B. E. Sobel. 1985. Quantification of choline and ethanolamine phospholipids in rabbit myocardium. Anal. Biochem. 144:65-74.

28. Bradford, M. 1976. A rapid and sensitive method for the quantitation of microgram quantities of protein utilizing the principle of protein-dye binding. Anal. Biochem. 72:248-254.

29. Gross, R. W. 1984. High plasmalogen and arachidonic acid content of canine myocardial sarcolemma: a fast atom bombardment mass spectroscopic and gas chromatography-mass spectroscopic characterization. Biochemistry. 23:158-165.

30. Gross, R. W., and B. E. Sobel. 1982. Lysophosphatidylcholine metabolism in the rabbit heart. J. Biol. Chem. 25:6702-6708.

31. Kates, M. 1972. Techniques of Lipidology. Isolation, Analyses and Identification of Lipids. In Laboratory Techniques in Biochemistry and Molecular Biology. T. S. Work and E. Work, editors. American Elsevier Publishing Co., New York. 377-379. 
32. Wolf, R. A., and R. W. Gross. 1985. Identification of neutral active phospholipase $\mathrm{C}$ which hydrolyzes choline glycerophospholipids and plasmalogen selective phospholipase $\mathrm{A}_{2}$ in canine myocardium. $J$. Biol. Chem. 260:7295-7303.

33. Rusznyák, I., M. Foldi, and G. Szabo. 1960. Lymphatics and Lymph Circulation. Pergamon Press, New York. 569-592.

34. Szlavy, L., D. F. Adams, N. K. Hollenberg, and H. L. Abrams. 1980. Cardiac lymph and lymphatics in normal and infarcted myocardium. Am. Heart J. 100:323-331.

35. Uhley, H. N., S. E. Leeds, and M. A. Sung. 1972. The subendocardial lymphatics of the canine heart. Am. J. Cardiol. 29:367-371.

36. Fournier, N. C., M. Zuker, R. E. Williams, and E. C. P. Smith. 1983. Self-association of the cardiac fatty acid binding protein: influence on membrane-bound, fatty acid-dependent enzymes. Biochemistry. 22: 1863-1872.
37. Sedlis, S. P., P. B. Corr, B. E. Sobel, and G. G. Ahumada. 1983. Lysophosphatidylcholine potentiates $\mathrm{Ca}^{2+}$ accumulation in rat cardiac myocytes. Am. J. Physiol. 244(Heart Circ. Physiol. 13):H32-H38.

38. Karli, J. N., G. A. Karikas, P. K. Hatzipavlou, G. M. Levis, and S. N. Moulopoulos. 1979. The inhibition of $\mathrm{Na}^{+}$and $\mathrm{K}^{+}$stimulated ATPase activity of rabbit and dog heart sarcolemma by lysophosphatidylcholine. Life Sci. 24:1868-1876.

39. Owens, K., F. F. Kennet, and W. B. Weglicki. 1982. Effects of fatty acid intermediates on $\mathrm{Na}^{+}-\mathrm{K}^{+}$-ATPase activity of cardiac sarcolemma. Am. J. Physiol. 242:H456-H461.

40. Knabb, M. T., J. E. Saffitz; P. B. Corr, and B. E. Sobel. 1986. The dependence of electrophysiologic derangements on accumulation of endogenous long-chain acyl carnitine in hypoxic neonatal rat myocytes. Circ. Res. 58:230-240. 